\title{
A Triple band Microstrip Antenna with Enhanced Bandwidth for Radar Applications
}

\author{
E. Kusuma Kumari, M. Vinod Kumar
}

\begin{abstract}
Here in this paper a triple band microstrip antenna is proposed. The designed antenna is of compact structure with dimensions $96 \mathrm{~mm} \times 27 \mathrm{~mm} \times 1.6 \mathrm{~mm}$ including ground plane which is fabricated using Fr-4 substrate with dielectric constant of 4.6.This antenna has three resonant frequencies which are working at $6.6 \mathrm{GHz}$ with bandwidth of $1.1 \mathrm{GHz}$ second band working at $8.3 \mathrm{GHz}$ with bandwidth of $200 \mathrm{MHz}$. and third operating frequency is $9.4 \mathrm{GHz}$ with bandwidth of $750 \mathrm{MHz}$. All the band obtained here are providing large bandwidth which have wide range of applications. The other antenna parameters like return loss, directivity, gain, VSWR and current distribution are mentioned in this paper. The main purpose of this antenna was to provide a single antenna for multiple applications and with improved bandwidth for transferring large amount of data. The designed antenna is suitable for industrial applications also as because of its compact structure and its wide range of applications like radar, communication satellites, radiolocation, navigation air traffic control etc.
\end{abstract}

Keywords-multiband antenna, Triple-band antenna, Defective Ground Structure.

\section{INTRODUCTION}

The term microwave is employed to explain magnetic attraction waves with wavelengths starting from $1 \mathrm{~cm}$ to $1 \mathrm{~m}$. The corresponding frequency vary is three hundred $\mathrm{MHz}$ to 300 gigahertz. This spectrum is restricted and needs to be shared, thus the demand for top performance RF/Microwave circuits is increasing that have high property and constant information measure is bit by bit increasing[1].In recent years, the shrinking of antennas has become additional and additional necessary thanks to the increasing demand for little antennas because the fast development in wireless communications[2].The advantages of microstrip antennas build them well-liked in several wireless communication applications like satellite communication measuring instrument, medical applications, aircraft, spacecraft, and missile applications at identical time disadvantages of Microstrip antenna is slender information measure, poor potency [3].

Thus, to improve the performance of microstrip antenna various techniques are used now a days one of which is DGS, in this we introduce some defects in ground plane anddepending on the shape and dimensions of the defect, the shielded current distribution in the ground plane is disturbed, resulting a controlled excitation and propagation of the electromagnetic waves through the substrate layer [4].

Revised Version Manuscript Received on 16 September, 2019.

Dr. E. KusumaKumari, Professor \& Head, ECE Department, Sri Vasavi Engineering College, Tadepalligudem, West Godavari,Andhra Pradesh, India.

M. Vinod Kumar, Asst. Professor, Sri Vasavi Engineering College, Tadepalligudem, West Godavari,Andhra Pradesh, India.
Various feeding techniques square measure used for transmission the magnetic attraction energy to a microstrip patch antenna. the task of feeding is incredibly necessary just in case of economical operation of antenna to enhance the antenna input electrical resistance matching [5]. the varied forms of feeding techniques square measure microstrip printing operation, co-axial feed, aperture coupled feed, proximity feed. The feeding used here during this antenna structure is microstrip printing operation during which a conducting strip is connected on to the sting of diverging patch. though many French telephone multiband antenna styles were projected [6],[7] they're either fed by microstrip lines [6],[7] or mini-coaxial cable [8].

This paper works for 3 bands with wide information measure applications below $\mathrm{C}$ band and $\mathrm{X}$ band. The antenna consists of 2 rectangular ring style of structures, and there a 2 stubs hooked up in it. The resonant frequencies we tend to have gotten ar as a result of these stubs as by variable their length there'll be variation in operative frequencies. we've additionally introduced the defect in ground plane as victimization this DGS technique the opposite antenna parameters were improved. The bandwidths measured here all follow the $-5 \mathrm{~dB}$ come back loss. The designed antenna is often used for radar, mobile applications, satellite applications, measuring instrument, military, traffic management etc.

This paper is in organized in four sections which are as follow. As the section I here give a grief introduction of proposed antenna. Section II, basic design of antenna is described, and fabricated structure is also included in it. In Section III, the simulated and measured results of designed antenna are presented and finally, the paper is concluded in Section IV.

\section{II.ANTENNA DESIGN}

In this section the basic design of proposed antenna is included. It includes both simulated as well as fabricated structure is explained. Figure 1 shows the structure of microstrip antenna both fabricated and simulated. Table lincludes the dimensional parameters of antenna. For input two-dimensional conductor variety of feeding is employed. within the structure for every aspect of feeding one rectangular ring is hooked up with that one stub is hooked up within. The antenna structure is intended exploitation Fr-4 substrate that have stuff constant $(\varepsilon r=4.6)$. The variation in in operation frequency and in antenna parameters is discovered 
by varied the length and breadth of stub. The come loss parameters is improved by dynamical the breadth of rectangular ring. the opposite antenna parameters square measure improved by introducing the defects in ground structure. By varied the bottom structure, we have a tendency to square measure varied the present distributing that helps in up the antenna parameters. the opposite dimensions of projected antenna square measure given in Table one.

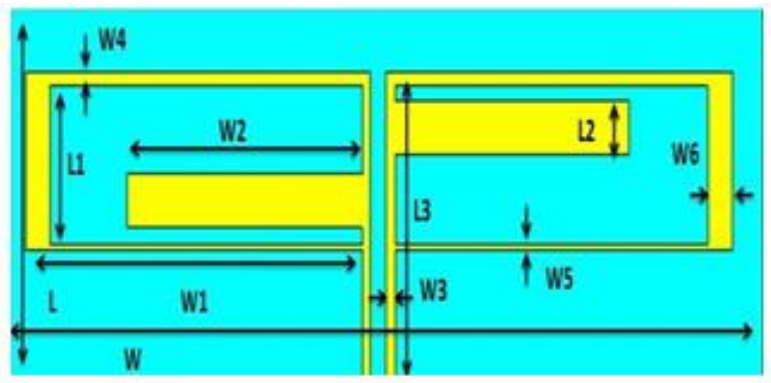

(a)

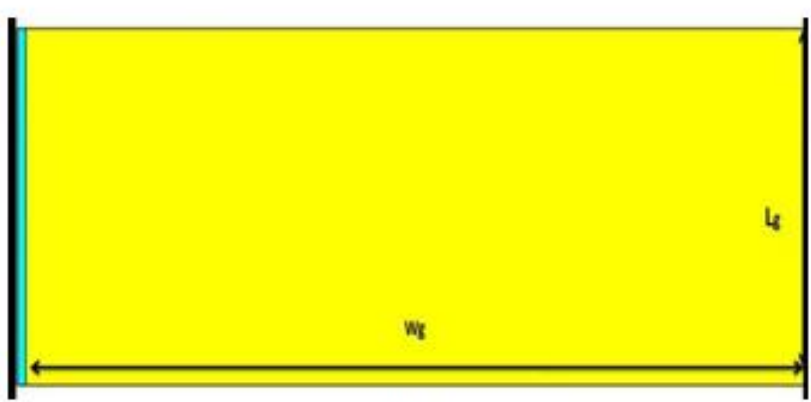

(b)

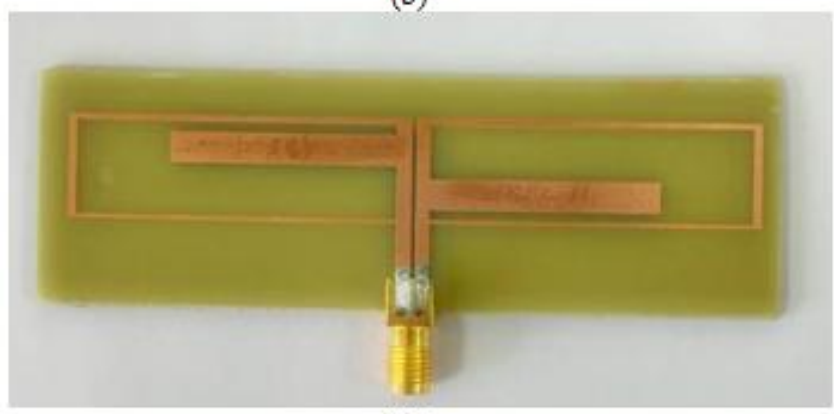

(c)

Fig.1 Proposed antenna structure (a)simulated structure front view. (b)simulated structure back view. (c) Fabricated structure

TABLE 1

KEY DIMENSIONS OF ANTENNA DESIGN

\begin{tabular}{|cccc|}
\hline Name & Dimensions & Name & dimensions \\
\hline L & $27 \mathrm{~mm}$ & W & $96 \mathrm{~mm}$ \\
\hline L1 & $11.2 \mathrm{~mm}$ & W1 & $39.8 \mathrm{~mm}$ \\
\hline L2 & $3.8 \mathrm{~mm}$ & W2 & $29.85 \mathrm{~mm}$ \\
\hline L3 & $22 \mathrm{~mm}$ & W3 & $1 \mathrm{~mm}$ \\
\hline W4 & $1 \mathrm{~mm}$ & W5 & $0.3 \mathrm{~mm}$ \\
\hline W6 & $3.15 \mathrm{~mm}$ & $\mathrm{Lg}$ & $27 \mathrm{~mm}$ \\
\hline Wg & $94.85 \mathrm{~mm}$ & & \\
\hline
\end{tabular}

\section{III.SIMULATION RESULTS AND ANALYSIS}

For simulation and optimization of proposed antenna electromagnetic simulation software CST is used. Various antenna parameters like return loss, radiation pattern and current distribution were observed and included in this section.

\section{A. Return Loss and VSWR}

The return loss graph is shown in fig. 2 from the figure antenna is working for three bands first band is from $6 \mathrm{Ghz}$ to $7.1 \mathrm{GHz}$ with the bandwidth of $1.1 \mathrm{GHz}$, return loss is $-35 \mathrm{~dB}$, second band is from $8.2 \mathrm{GHz}$ to $8.4 \mathrm{GHz}$ with a bandwidth of $200 \mathrm{MHz}$ return loss is $-20 \mathrm{~dB}$, and the third band is from $9 \mathrm{GHz}$ to $9.745 \mathrm{GHz}$ with a band width of $745 \mathrm{MHz}$ return loss is $-30 \mathrm{~dB}$ as shown in Fig.2(a) Fig2(b) shows the measured results. From the graphs both the simulated and measured results are showing good similarity in their results.

Fig3. shows the graph for VSWR of antenna. For the operating frequency the VSWR should be less than 2. From the graph for three bands (first band is from $6 \mathrm{Ghz}$ to $7.1 \mathrm{GHz}$ with the bandwidth of $1.1 \mathrm{GHz}$, second band is from $8.2 \mathrm{GHz}$ to $8.4 \mathrm{GHz}$ with a bandwidth of $200 \mathrm{MHz}$ and the third band is from $9 \mathrm{GHz}$ to $9.745 \mathrm{GHz}$ with a band width of $745 \mathrm{MHz}$.) VSWR is less than 2.

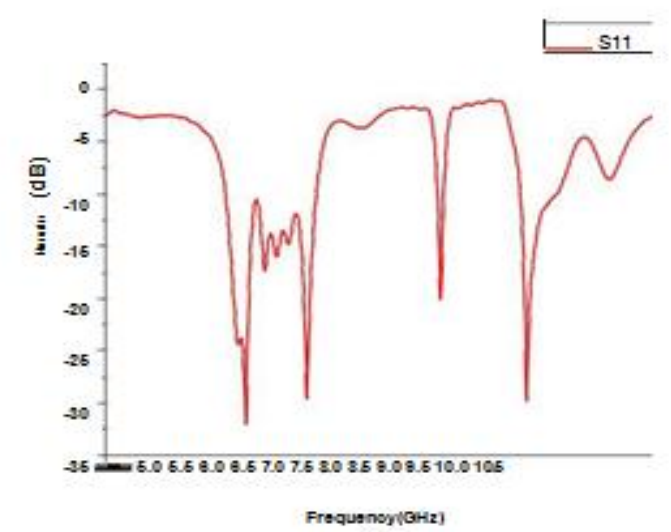

(a)

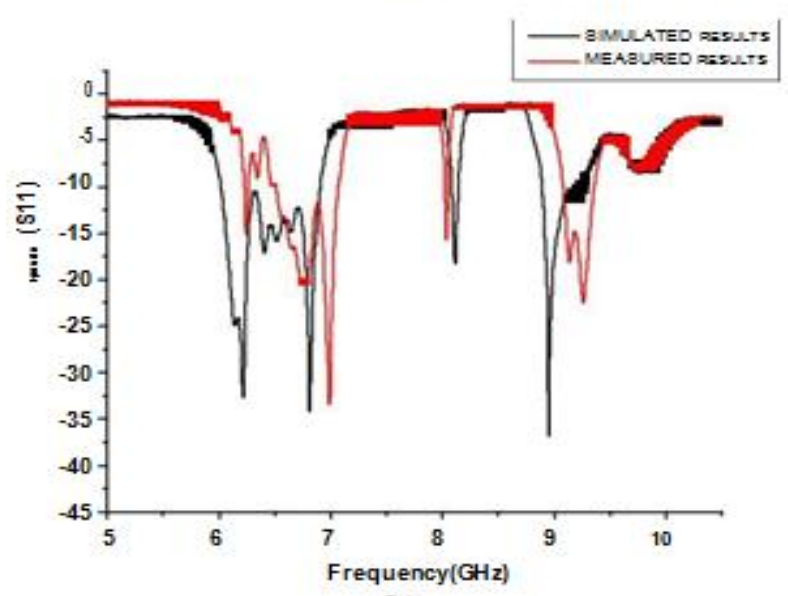

(b)

Fig.2 Return loss (a) simulated (b) comparative result of simulated andmeasured 


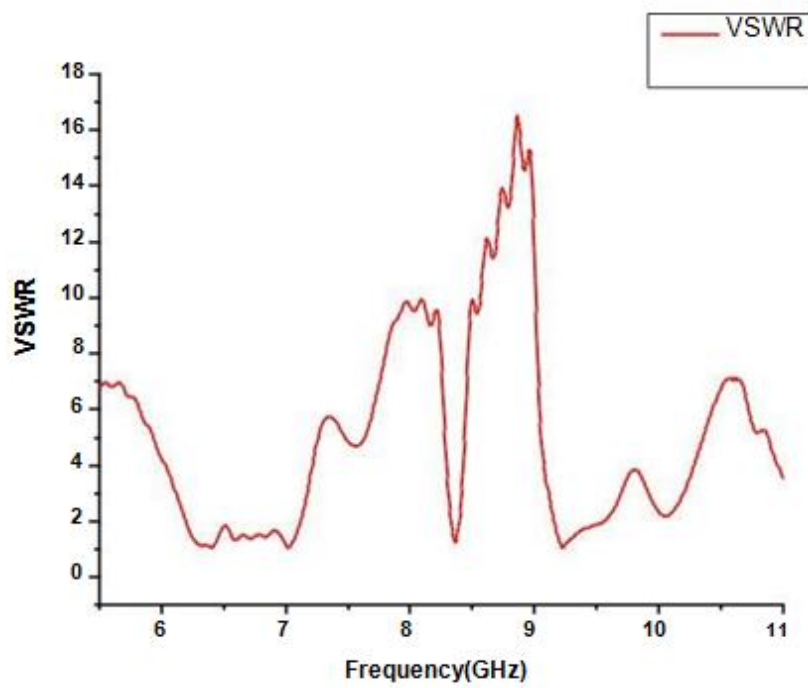

Fig.3. Simulated VSWR

B. Radiation pattern

Farfield Directivity Abs (Phi=0)

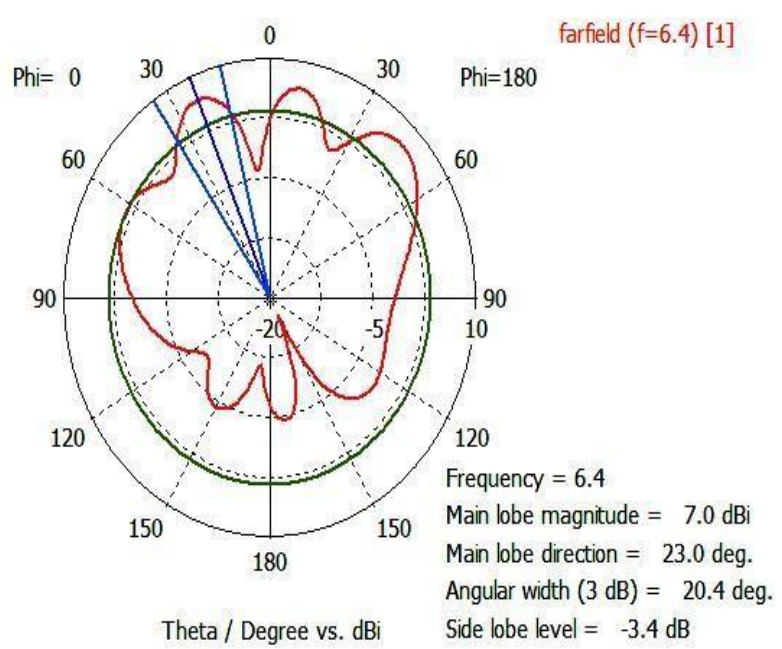

(a)

Farfied Drectivity Abs (Phi $=0$ )

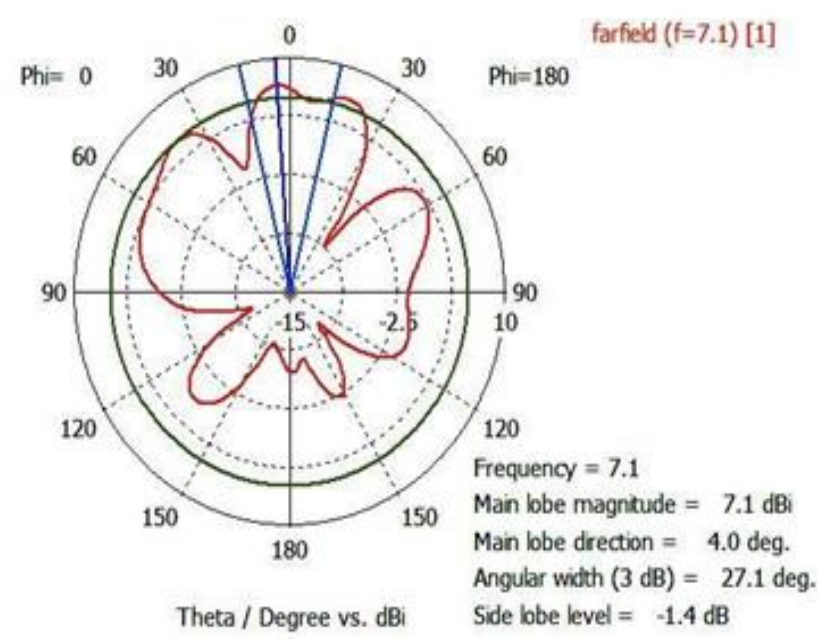

(b)

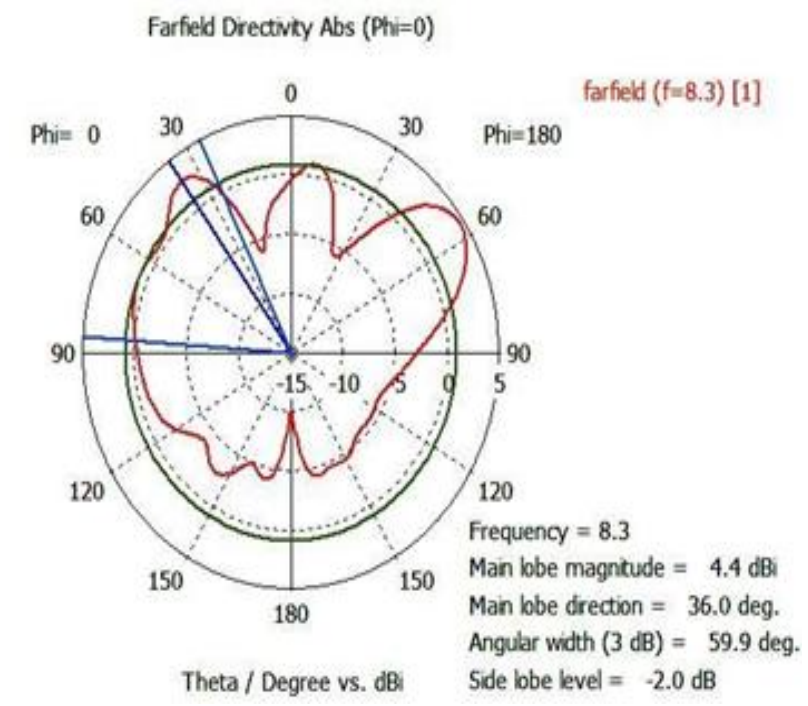

(c)

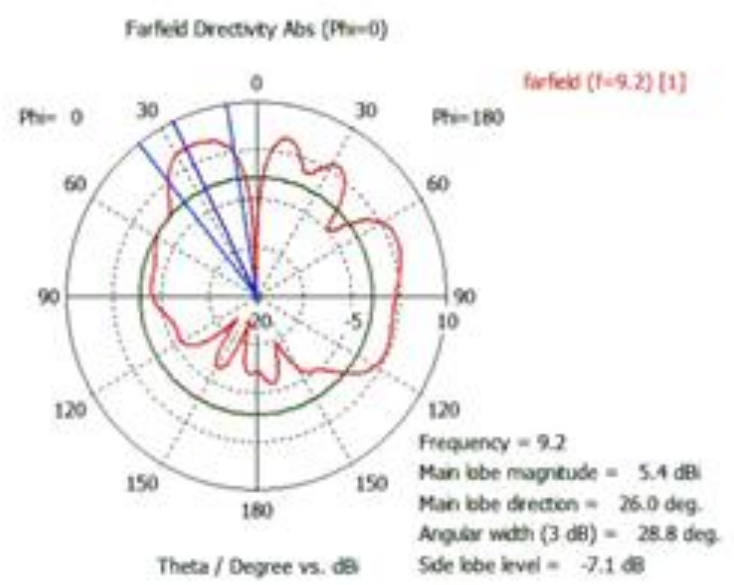

(d)

Fig.4 Directivity at (a)6.4GHz (b)7.1GHz (c)8.3GHz (d) $9.2 \mathrm{GHz}$

\section{Surface Current Distribution}

Surface current in an antenna shows the flow of current in the antenna. It shows the current density as where the current is maximum, and it is shown by dark areas and where the current density is low it is shown by light shaded area. Fig.5 shows the surface current distribution at all the resonant frequencies. From the entire figure it can be concluded that near the of comb like antenna structure maximum current is flown. 


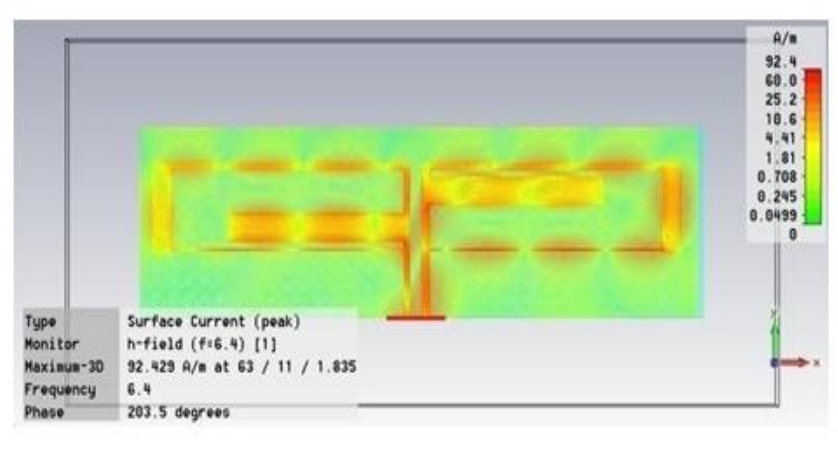

(a)

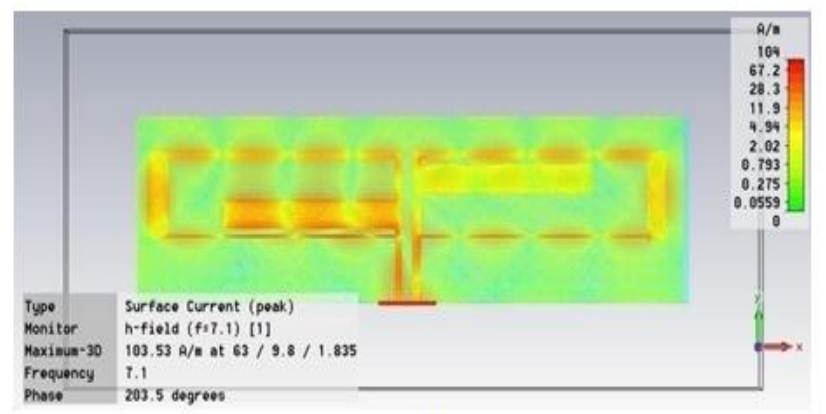

(b)

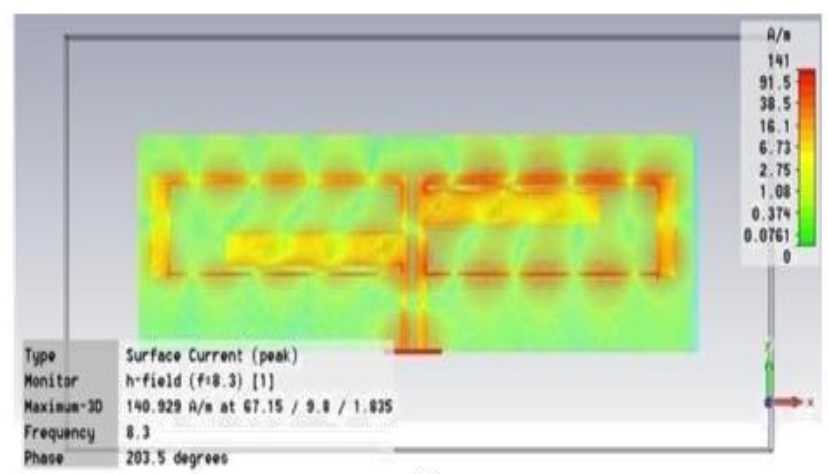

(c)

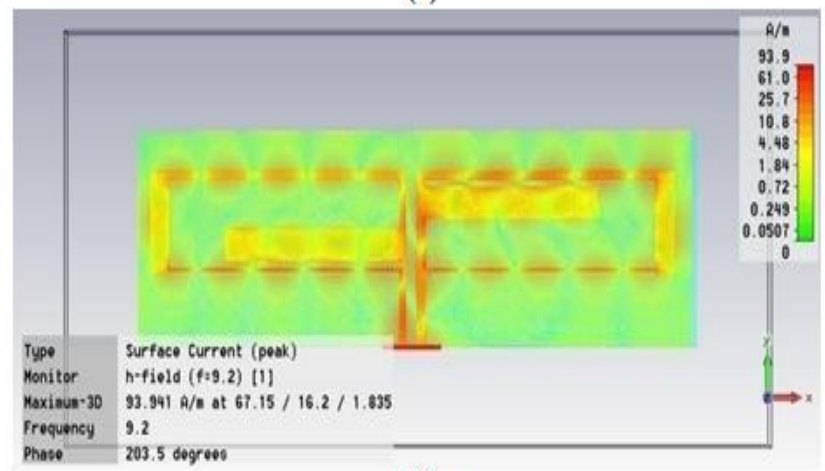

(d)

Fig.5 Surface current distribution at different resonant frequencies

\section{IV.CONCLUSION}

A triple band micro strip antenna is proposed in this paper. The antenna is improved from its last structure [1] as in that it was working for six different bands while their bandwidth was not good, so this new structure shows three bands working for various applications as the bands have wide bandwidth. The structure has two rectangular hollow patches and one stub in each rectangular patch. The three bands achieved have wide bandwidth the first band is from $6 \mathrm{Ghz}$ to $7.1 \mathrm{GHz}$ with the bandwidth of $1.1 \mathrm{GHz}$, second band is from $8.2 \mathrm{GHz}$ to $8.4 \mathrm{GHz}$ with a bandwidth of $200 \mathrm{MHz}$ and the third band is from $9 \mathrm{GHz}$ to $9.745 \mathrm{GHz}$ with a band width of $745 \mathrm{MHz}$. The bandwidths measured here all follow the $-5 \mathrm{~dB}$ return loss. The designed antenna can be used for weather radar, mobile applications, satellite applications, radiolocation, military, air traffic control etc.

\section{REFERENCES}

1. M. RincyJuliet, R. Vallikannu, BC. Kavitha "A Novel style of HybridMicrowaveBandpass filter mistreatment lumped component and microstrip line technology" 2017 International Conference on Intelligent Computing and management (I2C2)

2. Rashmi A. Pandhare, Prasanna L. Zade , Mahesh P.Abegaonkar,"Miniaturized microstrip antenna array mistreatment defected groundstructure with increased performance",JESTCH,19(2016) 1360-1367"

3. Kiminami, K., Hirata, A., and Shiozawa, T., "Double-SidedPrinted Bow- Tie Antenna For UWB Communications",IEEE Antennas Wirel. Propag. Lett., 2004, 3, Pp. 152 - 153.

4. Ashwini K. Arya, M.V. Kartikeyan, A.Patnaik, "Defected Ground Structure within the perspective of Microstrip Antennas: A Review" ,Frequenz sixty four (5-6)(2010),DOI: 10.1515/FREQ.2010.64.5-6.79

5. Antenna AnushiArora, Hindu deity Khemchandani , YashRawat, ShashankSinghai, andGauravChaitanya, "Comparative study of various Feeding Techniques for Rectangular Microstrip Patch" international journal of innovative analysis in electrical, physics, instrumentation and management engineering Vol. 3, Issue 5, May 2015.

6. J.-S. Choi, K.-K. Kang, J.-W. Lee, C.-S. Cho, and J. Kim. "A performance investigation of an interior quad-band antenna with double-spiral structures," IEEE Antennas Wirel. Propag. Lett., vol. 5, no.1, pp. 552-555, Dec. 2006.

7. Dr. E. KusumaKumari, "Improved Performance of Patch Antenna based mostly on Comparative Analysis between geometry and Defected Ground Structure" 2018 JETIR Gregorian calendar month 2018, Volume 5, Issue four computer network.jetir.org (ISSN-2349-5162)

8. H.-J. Liu, R.-L. Li, Y. Pan, X.-L. Quan, L. Yang, and L. Zheng. "AMulti-broadband flattened antenna for GSM/UMTS/LTE and WLAN/WiMAX handsets," IEEE Trans. Antennas and Propag., vol. 62,no. 5, May, 2014.

9. C.-M. Peng, I.-F. Chen, C.-C. Hung, S.-M. Shen, C.-T. Chien, and C.-C.Tseng. "Bandwidth improvement of internal antenna by using reactiveloading for penta-band mobile handsetapplication,"IEEE Trans.Antennas and Propag., vol. 59, no.5, pp. 1728-1733, May, 2011. 